\title{
Operando X-ray absorption spectroscopy probing dynamic processes in batteries
}

\author{
Moniek Tromp \\ University of Groningen, Faculty of Science and Engineering, Zernike Institute for Advanced Materials, Materials Chemistry, \\ Nijenborgh 4, 9747 AG Groningen, \\ Moniek.Tromp@rug.nl
}

An important element in the reduction of $\mathrm{CO}_{2}$ is the change of vehicles with internal combustion engines to electric battery powered vehicles. The as such produced renewable energy can be used for individual mobility as well as for a temporary intermediate storage of excess energy. A viable electric mobility concept requires however stable cycle batteries with high specific energy (minimising weight, maximising driving range).

$\mathrm{Li}$ ion batteries are widely used in applications such as mobile phones and laptops and will likely be key to future electromobility. An alternative promising battery is the lithium sulfur battery with a potential twofold energy density increase. The requirements for such batteries present major challenges, e.g. energy capacity, deactivation/stability and safety. A detailed understanding of the charge, discharge and deactivation mechanisms are thus required, preferably quantitative and spatially resolved. X-ray absorption spectroscopy (XAS) is a characterisation technique which provides detailed electronic and structural information on the material under investigation, in a time- and spatially resolved manner.

Here, I will explain the strengths and limitations of XAS for battery research. A novel operando XAS cell design will be described [1], including the challenges to perform reliable experiments (electrochemically and spectroscopically). The cell allows time and spatial resolved XAS, providing insights in the type, location and reversibility of the intermediates formed in electrodes and electrolyte separately. Obtained insights in cycling and deactiviation mechanisms for the different battery types will be discussed [1-6] and future research directions described.

[1] Y. Gorlin, A. Siebel, M. Piana, T. Huthwelker, H. Jha, G. Monsch, F. Kraus, H.A. Gasteiger, M. Tromp, J. Electrochem. Soc. 162(7): A1146A1155, 2015.

[2] Y. Gorlin, M. U. M. Patel, A. Freiberg, Q. He, M. Piana, M. Tromp, H. A. Gasteiger, J. Electrochem. Soc. 2016, 163(6), A930-A939.

[3] J. Wandt, A. Freiberg, R. Thomas, Y. Gorlin, A. Siebel, R. Jung, H. A. Gasteiger, M. Tromp, J. Mater. Chem. A 2016, 4, $18300-18305$.

[4] A. T. S. Freiberg, A. Siebel, A. Berger, S. M. Webb, Y. Gorlin, H. A. Gasteiger, M. Tromp, J. Phys. Chem. C 2018, 122 , 10, $5303-5316$.

[5] A. Berger, A. T. S. Freiberg, R. J. Thomas, M. U. M. Patel, M. Tromp, H. Gasteiger, Y. Gorlin, J. Electrochem. Soc. 2018, 165(7), A1288A1296.

[6] R. Jung, F. Linsenmann, R. J. Thomas, J. Wandt, S. Solchenbach, F. Maglia, C. Stinner, H. A. Gasteiger, M. Tromp, J. Electrochem. Soc. 2019, 166(2): A378-A389.

Keywords: novel operando XAS cell design

Acta Cryst. (2021), A77, C683 